\title{
わずかな密度差を利用した固気流動層による 珪石とろう石の比重分離
}

\author{
Separation of Silicastone and Pyrophyllite by Gas-Solid \\ Fluidized Bed Utilizing Slight Difference in Density
}

\author{
押谷 潤 ${ }^{a}$ ，近藤 松次郎 ${ }^{b}$, 西 博之 ${ }^{a}$, 田中 善之助 ${ }^{a}$ \\ Jun Oshitani, Matsujiro Kondo, Hiroyuki Nishi, Zennosuke Tanaka
}

\begin{abstract}
Separation of silicastone and pyrophyllite due to density difference with a gas-solid fluidized bed is investigated. We employ mixtures of glass beads and steel shots with various mixing ratios as a fluidizing medium to obtain fluidized beds of various bulk densities. Floating and sinking of the ores in the fluidized bed are examined by changing the bulk density and superficial velocity. It is found that the separation of two ores with slight density difference is possible at a high separation efficiency by careful adjustment of the mixing ratio. The separation efficiency depends on the superficial velocity because it alters the flow patterns of particles and bubbles in the fluidized bed, which affect the floating and sinking of ores.
\end{abstract}

Key Words : Separation, Fluidized bed, Silicastone, Pyrophyllite, Glass beads, Steel shots

\section{1. 緒 言}

鉱石は，我々の日常生活を豊かにし，現代の産業活 動を維持するための重要な資源の一つであるが, 長年 にわたる採掘により，その埋蔵量は減少の一途をたど っている。特に，良質な鉱石量の減少に伴う貧鉱化が 問題となっており，多成分の混合釷石から有用鉱石を 高効率かつ低コストで分離可能な選鉱技術の開発が望 まれている。従来，選鉱技術として浮遊選釷法や重液 選鉱法が主に用いられている1.2)。しかし，浮遊選鉱 法では，高い分離効率を得るために捕集剂や起泡剂, 活性剂など多種多様な添加剂を必要とし，重液選鉱法 では，此重差が 1 を下回る場合では高効率の分離が困 難であると言われている。いずれの方法も液体を用い る湿式法であり, 廃液処理を必要とするほか, 鈗毒水 などの鉱害を招く恐れもある。また，人による目視選 別も一般的に行われており，低い分離効率や高い人件

2000 年 7 月 27 日受付

$a$ 岡山大学工学部物質応用化学科

（テ700-8530 岡山市津島中 3-1-1）TEL 086-251-8086

Department of Applied Chemistry, Okayama University

(3-1-1, Tsushima-naka, Okayama 700-8530)

$\mathrm{b}$ 株式会社大平

（テ705-0131 岡山県備前市野谷443-1） TEL 0869-62-0531

Ohira Co. Ltd.

(443-1, Nodani. Bizen-shi, Okayama 705-0131)
費が問題となっている。

そこで本研究では, 上述の問題を抱えない“固気流 動層による乾式比重分離の原理”を選鉱技術に応用利 用することを試みた。粉体を下部からの送風で流動化 させた固気流動層は, 密度や粘度などの液体に類似し た性質を持つことが一般的に知られている3.4)。従っ て, 固気流動層のかさ密度よりも軽い物体は層内で 浮揚し，重い物体は沈降する。著者らは，これまで に同原理を利用して低品位炭から良質石炭を連続的 かつ高効率で分離回収可能な技術開発に成功してお $り^{5)}$ ，現在，実用化に向けた試験段階にある。本研究 では，分離対象物として珪石とろう石を用いた。珪 石とは, $\mathrm{SiO}_{2}$ 分を多く含み工業的に利用される珪酸 質原料の総称であり, ガラス用，鉄鋼用，耐火材用 などが主な用途である ${ }^{6)}$ 。ろう石とは，葉万う石 $\left(\mathrm{Al}_{2}\left(\mathrm{Si}_{4} \mathrm{O}_{10}\right)(\mathrm{OH})_{2}\right)$ を主に含む鉱石であり，耐火棟 瓦や陶磁器原料, 紙や織物の充填剂, ゴム増強剂など に用いられる ${ }^{6.7)}$ 。長年の採掘及び埋蔵量の減少に伴 う貧鉱化から，現在，珪石とろう石の混合石が主に採 掘されており，これらを分離する技術が求められてい る。珪石とろう石の分離に適したかさ密度を実現する ために, ガラスビーズとスチールショットの湿合粉体 を分離媒体として用い，様々な密度を持つ球の浮沈に より流動化状態でのかさ密度を求めた。珪石とろう石 
Table 1 Characteristics of powders employed

\begin{tabular}{lccc}
\hline & Particle diameter $(\mu \mathrm{m})$ & True density $\left(\mathrm{kg} / \mathrm{m}^{3}\right)$ & Bulk density $\left(\mathrm{kg} / \mathrm{m}^{3}\right)$ \\
\hline Glass beads & $180-250$ & 2500 & 1500 \\
Steel shots & $45-106$ & 7600 & 4300 \\
\hline
\end{tabular}

の密度差は約 $250 \mathrm{~kg} / \mathrm{m}^{3}$ とわずかであり，しかも層 内の粒子や気泡の流れが鉱石の浮沈に与える影響も大 きく，両鉱石の分離は困難なことが予想される。従っ て, 粉体の混合割合や分離を行う際の空塔速度, 及び 鉱石投入後の流動化時間など実験条件を様々に変化さ せ, どの程度高い分離効率が得られるのかを検討し た。

\section{2. 実験}

\section{1 鉱石と流動化粉体}

鉱石として，珪石とろう石を 20 個づつ用いた。 Fig. 1 に，それらの密度分布と球相当径を示す。珠石 は $2300 \sim 2550 \mathrm{~kg} / \mathrm{m}^{3}$ の広範囲に分布し, $2500 \mathrm{~kg} /$ $\mathrm{m}^{3}$ にピークを持つ。一方， ろう石は $2650 \sim 2750$ $\mathrm{kg} / \mathrm{m}^{3}$ の狭い範囲に分布し, $2700 \mathrm{~kg} / \mathrm{m}^{3}$ にピークを 持つ。球相当径は共に $10 \sim 50 \mathrm{~mm}$ の範囲にあり, 珪 石は $30.5 \pm 8.6 \mathrm{~mm}$ ， 万う石は $30.3 \pm 8.1 \mathrm{~mm}$ であ る。

流動化粉体として, Table 1 に示す粒径, 真密度, かさ密度を持つガラスビーズ（G.B.）とスチールショ ット（S.S.）を用いた。これらを混合して流動化させ た場合, 珪石とろう石の密度の間にかさ密度を調整す ることが可能である。偏析が生じることなく両粉体を 混合させるため, 後の結果に示すように最小流動化速 度が比較的近くなるように G.B. と S.S. の粒径を決定 した。

\section{2 実験装置}

Fig. 2 に実験装置の概略図を示す。流動層は厚さ $5 \mathrm{~mm}$ のアクリル円筒管からなり, 内径 $20.5 \mathrm{~cm}$, 高 さ $48 \mathrm{~cm}$ である。層底部には, 穴径 $3 \mathrm{~mm}$ ，ピッチ $6 \mathrm{~mm}$, 開孔率 $22.67 \%$ のステンレス多孔板 2 枚で厚 さ $1 \mathrm{~mm}$ のフェルト布地を挟んだ空気分散板を設け た。流動層内に G.B. と S.S. を所定のかさ体積割合で 混合したものを高さ $15 \mathrm{~cm}$ となるように仕込み，ブ ロワーにより空気を送り込んでモーターバルブの開閉 により空塔速度を微調整した。オリフィス流量計の圧 力及び流動層底部と大気間の圧力差を圧力センサーに より電圧值として読み取り, あらかじめ得られている 電圧一空塔速度及び電圧一圧力損失の関係式を用いて
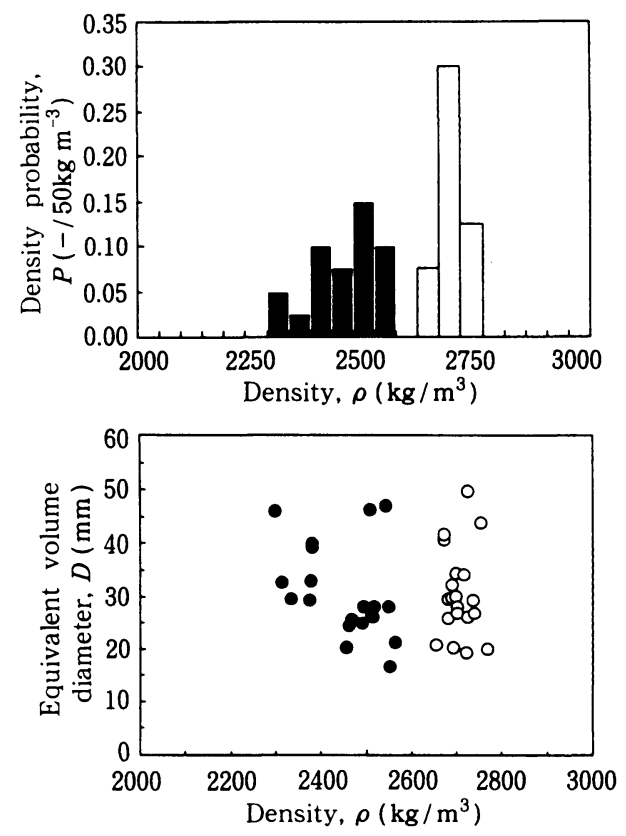

Fig. 1 Density and diameter distributions of silicastone and pyrophyllite (black : silicastone, white : pyrophyllite)

空塔速度と压力損失を求めた。

\section{3 流動化状態でのかさ密度の測定}

$1700 \sim 3600 \mathrm{~kg} / \mathrm{m}^{3}$ の範囲で $10 \mathrm{~kg} / \mathrm{m}^{3}$ 毎に密度調 整した直径 $37.5 \mathrm{~mm}$ の球（ピンポン球に S.S. を詰め たもの）を用意した。粉体層を流動化させて最上層の 中心部に球を投入し， 5 分後に送風を止め，層底部か らの球の重心位置 $h_{\mathrm{sp}}$ を測定した。測定は各実験条件 下で 3 回行った。球の密度が流動層のかさ密度より小 さければ球は浮揚し, 同程度の場合には中層に位置 し, 大きければ沈降する。各密度の球について $h_{\mathrm{sp}}$ を 求め, 中層に位置する球の密度範囲を平均して流動層 のかさ密度とした。

\section{4 鉱石の浮沈及び分離評価法}

粉体層を流動化させて最上層の中心部に鉱石 1 個を 投入し, 所定時間放置した後に送風を止め, 層底部か らの鉱石の重心位置を測定した。全ての鉱石について 重心位置を求め, 各位置 $i$ に存在する鉱石の個数割合 


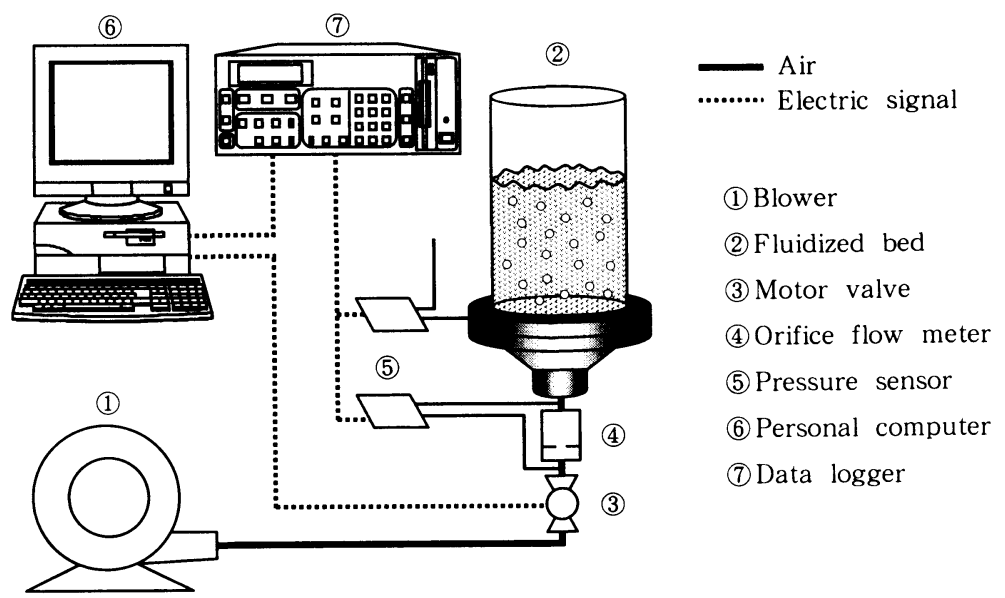

Fig. 2 Schematic drawing of the experimental apparatus

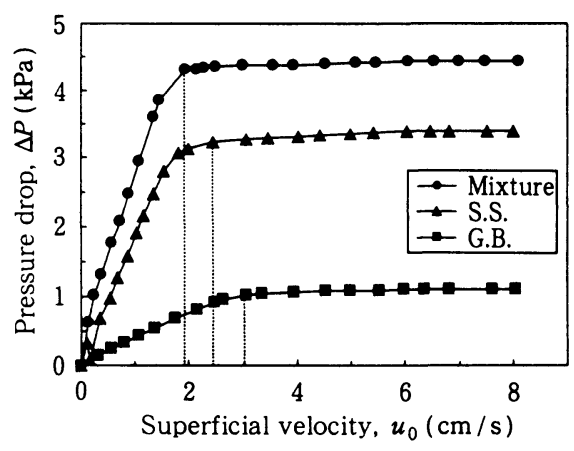

Fig. 3 Dependence of pressure drop on superficial velocity $\left(V_{\text {s.s. }}=0.50\right.$ for mixture)

$x_{\mathrm{i}}$ を求めた。 $i$ は層底部から $1 \mathrm{~cm}$ 毎の高さを表し, 例 えば $5 \mathrm{~cm} \sim 6 \mathrm{~cm}$ の場合 $i=6$ とする。鈗石の浮沈を表 すパラメーターとして，Eg. (1) で定義される浮沈係 数 $x_{\mathrm{f}-\mathrm{s}}$ を, 珪石とろう石のそれぞれについて求め た。

$$
x_{\mathrm{f}-\mathrm{s}}=\sum_{i=2}^{15} \frac{i-2}{13} \cdot x_{\mathrm{i}}
$$

ここで, 鉱石の球相当径は約 $30 \mathrm{~mm}$ であり, 鉱石が 完全に沈降する場合では鉱石の重心が $i=2$ に位置し たため, $i$ の最小值として 2 を用いた。浮沈係数は, 浮揚する鉱石の割合が多いほど 1.0 に近づき, 沈降す る割合が多いほど 0.0 に近づくように定義されてい る。 $x_{\mathrm{f}-\mathrm{s}}=0.5$ は様々な浮沈状態を表すが, 本研究で は高さ方向でのほぼ一様な鉱石の分布を表す結果とな っている。また，珪石とろう石の分離を評価するパラ メーターとして，Eq. (2) で定義される浮沈係数差

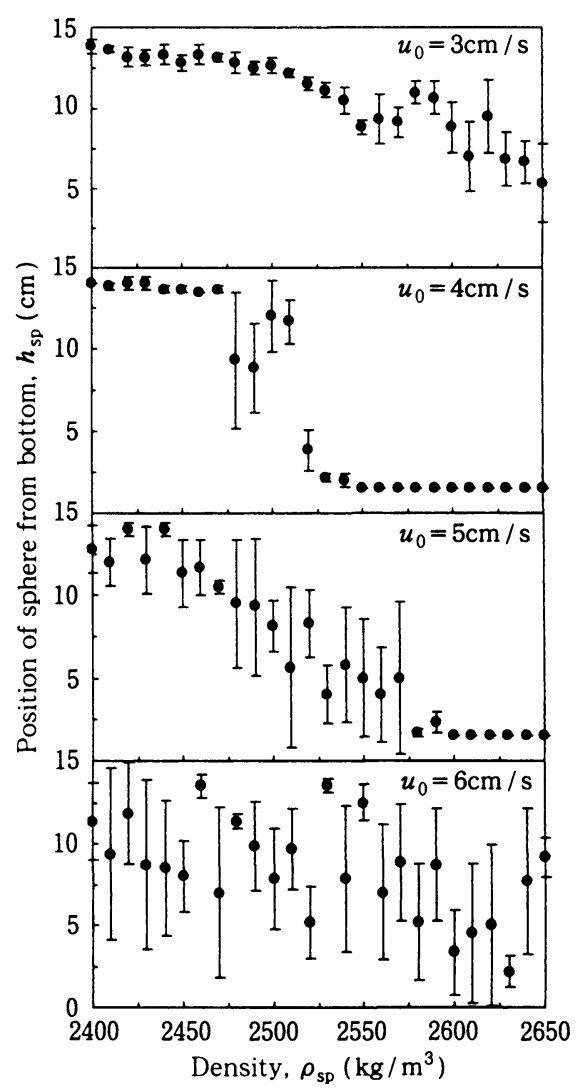

Fig. 4 Dependence of position of sphere from bottom on density for various superficial velocities $\left(V_{\text {s.s. }}=0.45\right)$

$\Delta x_{\mathrm{f}-\mathrm{s}}$ を求めた。この值が 1.0 に近いほど，両鉱石の 分離効率が高いことを示す。 


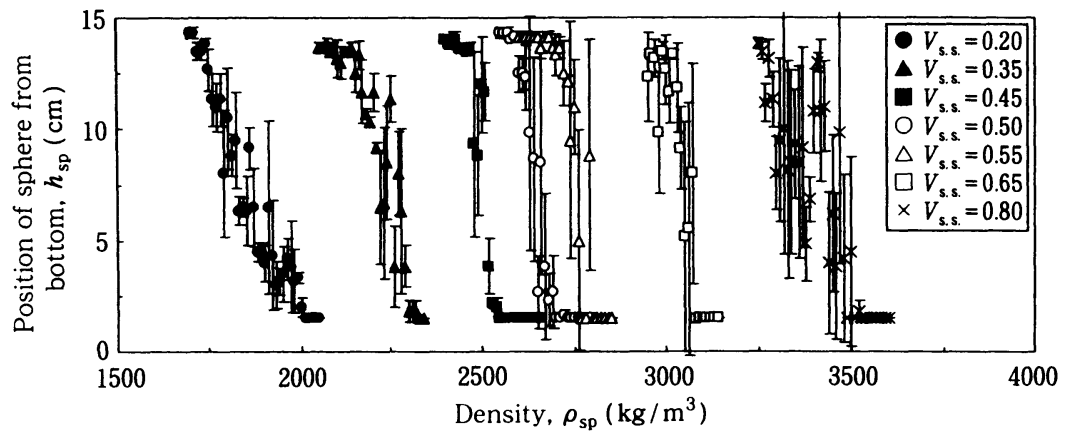

Fig. 5 Dependence of position of sphere from bottom on density for various bulk volume fractions of S.S. $\left(u_{0}=4 \mathrm{~cm} / \mathrm{s}\right)$

$$
\Delta x_{\mathrm{f}-\mathrm{s}}=\left|x_{\mathrm{f}-\mathrm{s}(\text { silicastone })}-x_{\mathrm{f}-\mathrm{s}(\text { pyrophyllite })}\right|
$$

鉱石の浮沈実験を各実験条件下で 3 回行い，珪石とろ う石の $x_{\mathrm{f}-\mathrm{s}}$ 及び $\Delta x_{\mathrm{f}-\mathrm{s}}$ の平均值と標準偏差をそれぞれ 求めた。

\section{3. 結果と考察}

\section{1 空塔速度と圧力損失}

流動層内に G.B. もしくは S.S. の単成分を高さ 7.5 $\mathrm{cm}$ 仕込んだ場合, 及び G.B. と S.S.の 2 成分を S.S. のかさ体積混合割合 $V_{\text {s.s. }}=0.50$ で混合したものを高 さ $15 \mathrm{~cm}$ 仕込んだ場合について, 空塔速度 $u_{0}$ を変化 させて圧力損失 $\Delta P$ を測定した。測定は，粉体層を $u_{0} \approx 8 \mathrm{~cm} / \mathrm{s}$ で数分間激しく流動化させた後に， $u_{0}$ を 徐々に減少させる過程で行った。Fig. 3 に結果を示 す。 $u_{0}$ が大きい場合では $\Delta P$ が一定であり，粉体層が 流動化していることを示している。最小流動化速度以 下では $\Delta P$ が直線的に減少しており, 粉体層が固定化 していることを示している。いずれの場合の最小流動 化速度も $2 \sim 3 \mathrm{~cm} / \mathrm{s}$ とほぼ同様の值を示している。 2 成分系では，偏析する場合によく見られる最小流動 化速度付近での圧力損失変化の湾曲 ${ }^{8)}$ が見られず, $u_{0} \geq 3 \mathrm{~cm} / \mathrm{s}$ では，偏析することなくG.B. と S.S. が混 合していることが目視によっても確認されている。

\section{2 流動化状態でのかさ密度}

S.S. のかさ体積混合割合 $V_{\text {s.s. }}=0.45$ で 2 成分を混 合した流動層について, 空塔速度 $u_{0}$ を変化させて $2400 \sim 2650 \mathrm{~kg} / \mathrm{m}^{3}$ の球の浮沈実験を行った。Fig. 4 に各 $u_{0}$ における球の密度 $\rho_{\mathrm{sp}}$ に対する球の位置 $h_{\mathrm{sp}}$ を示す。 $u_{0}=4 \mathrm{~cm} / \mathrm{s}$ では, $2400 \sim 2470 \mathrm{~kg} / \mathrm{m}^{3}$ の球 はほぼ完全に浮揚し，2530～2650kg/ $\mathrm{m}^{3}$ の球はほ ぼ完全に沈降した。2480〜2520kg/ $\mathrm{m}^{3}$ の球は中層 に位置し, 流動化状態でのかさ密度としてそれらの平

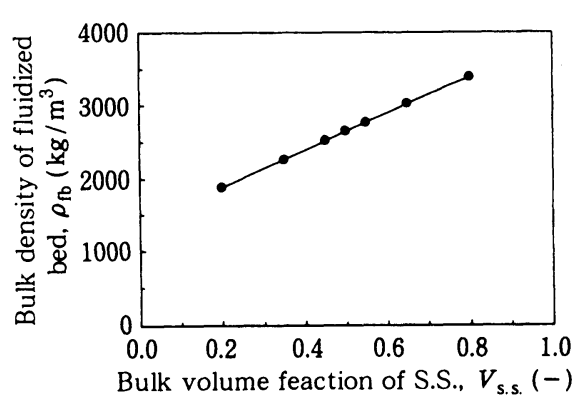

Fig. 6 Dependence of bulk density of fluidized bed on bulk volume fraction of S.S. and fitted straight line $\left(u_{0}=4 \mathrm{~cm} / \mathrm{s}\right)$

均值である $2500 \mathrm{~kg} / \mathrm{m}^{3}$ が得られた。 $u_{0}=3 \mathrm{~cm} / \mathrm{s}$ で は, $u_{0}=4 \mathrm{~cm} / \mathrm{s}$ の場合と比較して密度の大きな球が 沈降しにくい結果となった。これは空塔速度が小さく 粉体層の流動性が低いためであると考えられる。 $u_{0}=5 \mathrm{~cm} / \mathrm{s}$ では, 密度の小さな球が浮揚しにくくな り， $u_{0}=6 \mathrm{~cm} / \mathrm{s}$ では，いずれの球も層内で不安定な 挙動を示した。これは空塔速度が大きくなるに連れて 粉体層の流動化が激しくなるためであると考えられ る。

$V_{\text {s.s. }}$ を変化させ, 流動化状態のかさ密度を比較的求 めやすい $u_{0}=4 \mathrm{~cm} / \mathrm{s}$ において球の浮沈実験を行っ た。Fig. 5 に各 $V_{\text {s.s. }}$ における球の密度 $\rho_{\mathrm{sp}}$ に対する球 の位置 $h_{\mathrm{sp}}$ を示す。 $V_{\text {s.s. }}$ が小さい場合及び大きい場合 では，原因は不明であるが，浮揚する球と沈降する 球の境を成す密度幅が大きい結果となった。一方, G.B. とS.S. がほぼ同かさ体積混合している場合で は，その密度幅が小さくなった。Fig.6に $V_{\text {s.s. }}$ に対す る流動化状態のかさ密度 $\rho_{\mathrm{fb}}$ を示す。 $V_{\text {s.s }}$ の増加に伴 い $\rho_{\mathrm{fb}}$ は直線的に増加しており, Eq. (3) で示される 近似式が得られた。ただし，上で述べたように $V_{\text {s.s. }}$ 


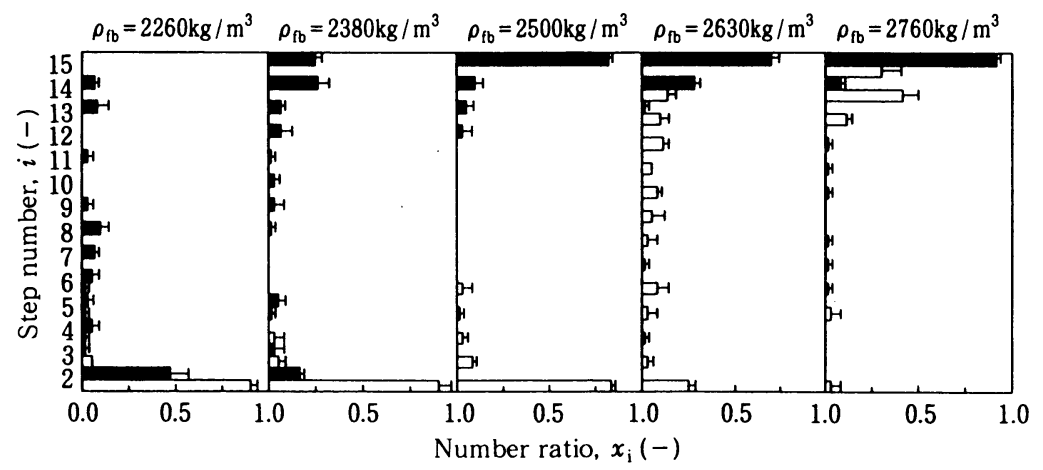

Fig. 7 Number ratio of silicastone and pyrophyllite at each step for various bulk densities (black : silicastone, white : pyrophyllite, $u_{0}=4 \mathrm{~cm} / \mathrm{s}, t=60 \mathrm{~s}$ )

が小さい場合及び大きい場合では，球が中層に位置 する密度範囲が広いために $\rho_{\mathrm{fb}}$ の值の精度は低くな る。

$$
\rho_{\mathrm{fb}} \approx 2500 V_{\mathrm{s.s.}}+1380
$$

\section{3 鉱石浮沈}

$0.35 \leq V_{\text {s.s. }} \leq 0.55$ の範囲で S.S. のかさ体積混合割合 $V_{\text {s.s. }}$ を変化させ, Eq. (3) より求まる様々なかさ密度 $\rho_{\mathrm{fb}}$ で珪石とろう石の浮沈実験を行った。Fig. 7 に各 $\rho_{\mathrm{fb}}$ における位置 $i$ に存在する鉱石の個数割合 $x_{\mathrm{i}}$ を示 す。珪石とろう石の密度よりも小さな $\rho_{\mathrm{fb}}=2260$ $\mathrm{kg} / \mathrm{m}^{3}$ では，いずれの鉱石とも沈降しやすい結果と なった。 $\rho_{\mathrm{fb}}=2380 \mathrm{~kg} / \mathrm{m}^{3}$ では，浮揚する珪石の割合 が多くなり， $\rho_{\mathrm{fb}}=2500 \mathrm{~kg} / \mathrm{m}^{3}$ では，上下層に珪石と ろう石が完全に分離する結果となった。 $\rho_{\mathrm{fb}}=2630$ $\mathrm{kg} / \mathrm{m}^{3}$ では，ろう石が各位置にほぼ一様に分布し， 珪石とろう石の密度よりも大きな $\rho_{\mathrm{fb}}=2760 \mathrm{~kg} / \mathrm{m}^{3}$ で は，いずれの鉱石とも浮揚しやすい結果となった。 Fig. 8 にかさ密度 $\rho_{\mathrm{fb}}$ に対する珪石とろう石の浮沈係 数 $x_{\mathrm{f}-\mathrm{s}}$ 及び浮沈係数差 $\Delta x_{\mathrm{f}-\mathrm{s}}$ を示す。珪石の $x_{\mathrm{f}-\mathrm{s}}$ は $\rho_{\mathrm{fb}}$ が大きくなるに連れて増加し， $\rho_{\mathrm{fb}} \geq 2500 \mathrm{~kg} / \mathrm{m}^{3}$ で $x_{\mathrm{f}-\mathrm{s}} \approx 1.0$ となりほぼ完全に浮揚した。一方，ろう 石の $x_{\mathrm{f}-\mathrm{s}}$ は $\rho_{\mathrm{fb}}$ が小さくなるに連れて減少し， $\rho_{\mathrm{fb}} \leq$ $2500 \mathrm{~kg} / \mathrm{m}^{3}$ で $x_{\mathrm{f}-\mathrm{s}} \approx 0.0$ となりほぼ完全に沈降し た。 $\Delta x_{\mathrm{f}-\mathrm{s}}$ は $\rho_{\mathrm{fb}}=2500 \mathrm{~kg} / \mathrm{m}^{3}$ で最大值 $0.95 \pm 0.01$ と なり, 珪石とろう石の平均密度の差が約 $250 \mathrm{~kg} / \mathrm{m}^{3}$ とわずかであるにもかかわらず，両者を上下層に高効 率で分離することが可能な興味深い結果となった。

Fig. 1に示されるように, 珃石とろう石を密度差を 利用して分離するには， $\rho_{\mathrm{fb}} \approx 2600 \mathrm{~kg} / \mathrm{m}^{3}$ が適すると 考えられる。しかし， $\rho_{\mathrm{fb}}=2630 \mathrm{~kg} / \mathrm{m}^{3}$ では $\Delta x_{\mathrm{f}-\mathrm{s}}=$ $0.51 \pm 0.01$ となり, しかも $\Delta x_{\mathrm{f}-\mathrm{s}}$ が最大值を示す

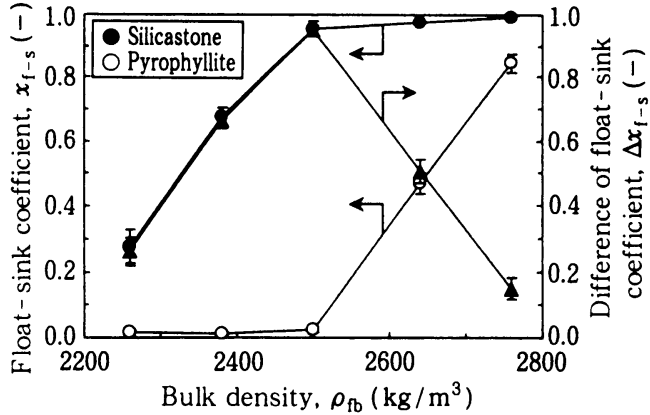

Fig. 8 Dependence of float-sink coefficient of silicastone and pyrophyllite and difference of float-sink coefficient on bulk density of fluidized bed $\left(u_{0}=4 \mathrm{~cm} / \mathrm{s}, t=60 \mathrm{~s}\right)$

$\rho_{\mathrm{fb}}=2500 \mathrm{~kg} / \mathrm{m}^{3}$ は珪石の密度分布の範囲内に存在す る。従って, 以上の結果は密度差通りの鉱石浮沈から 得られたとは言い難い。このような結果が得られた理 由として, 次のように考えられる。固気流動層内には 粒子や気泡の流れが存在するため, 層内に投入された 物体の浮沈は密度差のみで決定されるのではなく, 層 内流れの物体への影響にも左右されると考えられる。 この影響は物体の大きさや形に依存すると考えられ， 密度が同じでもより小さく軽い物体の方が層内流れの 影響を受けやすいと推察される。上で示されている $\rho_{\mathrm{fb}}$ の值は直径 $37.5 \mathrm{~mm}$ の球の浮沈より得られたもの であり，それとは大きさや形の異なる鉱石には球とは 異なる層内流れの影響が及ぶため，同じ密度を持つ球 と鉱石で浮沈に違いが見られたのではないかと考えら れる。

珪石とろう石を高効率で分離可能な $\rho_{\mathrm{fb}}=2500 \mathrm{~kg} /$ $\mathrm{m}^{3}$ において, 各空塔速度で鉱石を投入した後の流動 化時間を変化させた。Fig.9に各空塔速度での流動化 

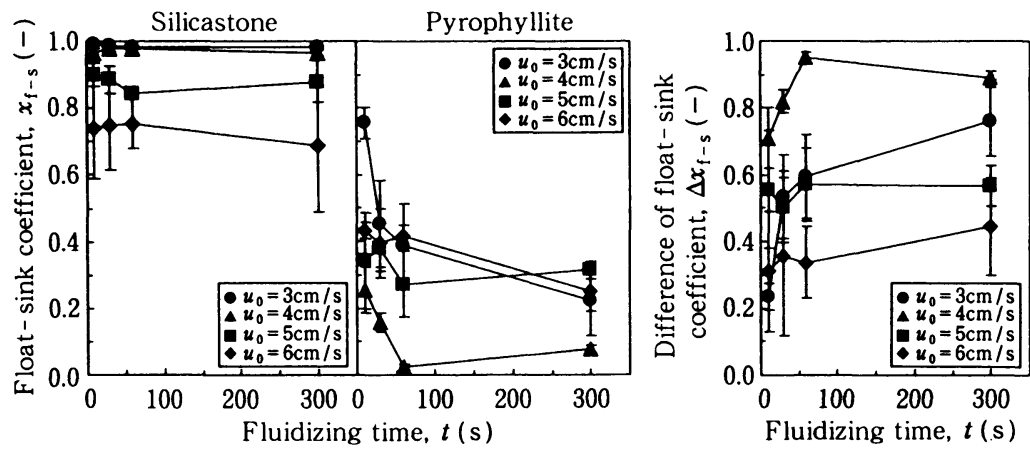

Fig. 9 Dependence of float-sink coefficient of silicastone and pyrophyllite and difference of float-sink coefficient on fluidizing time for various superficial velocities $\left(\rho_{\mathrm{fb}}=2500 \mathrm{~kg} / \mathrm{m}^{3}\right)$

時間 $t$ に対する珪石とろう石の浮沈係数 $x_{\mathrm{f}-\mathrm{s}}$ 及び浮沈 係数差 $\Delta x_{\mathrm{f}-\mathrm{s}}$ を示す。珪石では，流動化時間を変化さ せてもその浮沈傾向にほとんど違いは見られないが, 空塔速度が大きくなるに連れて浮揚しにくい結果とな った。これは空塔速度の増加に伴い層内流れが激しく なり，珪石がその流れに巻き込まれるためであると考 えられる。一方，ろう石では，いずれの空塔速度にお いても沈降するのにある程度の時間を必要とする結果 となった。 $u_{0}=3 \mathrm{~cm} / \mathrm{s}$ の場合の方が $u_{0}=4 \mathrm{~cm} / \mathrm{s}$ の場 合よりも沈降するのに長い時間を必要とするのは, 上 で述べたように空塔速度が小さい場合では粉体層の流 動性が低いためであると考えられる。 $u_{0}=5 \mathrm{~cm} / \mathrm{s}$ 及 び $u_{0}=6 \mathrm{~cm} / \mathrm{s}$ では, 珪石と同様に層内の激しい流れ にろう石が巻き込まれるために沈降しにくい結果にな ったと考えられる。浮沈係数差は，いずれの空塔速度 においても流動化時間と共に増加し，ある時間でほぼ 一定値を示した。これは，時間が経過するに連れてろ う石が沈降するためである。 $u_{0}=3 \mathrm{~cm} / \mathrm{s}$ では流動化 時間をさらに長くするとろう石がより沈降すると見込
まれ，浮沈係数差が 1.0 に近づくと考えられる。しか し，短時間で珪石とろう石を分離するためには，これ までの実験で採用されてきた $u_{0}=4 \mathrm{~cm} / \mathrm{s}, t=60 \mathrm{~s}$ が 本装置での最適な条件と言える。

\section{4. 結言}

固気流動層による乾式比重分離の原理を利用し， G.B. とS.S. の混合粉体を用いて密度差のわずかな珪 石とろう石の分離を試み，以下の結論を得た。

1 ） G.B. と S.S. の混合割合を変化させ，かさ密度を 精度良くコントロールすることで, 密度差が約 250 $\mathrm{kg} / \mathrm{m}^{3}$ とわずかであるにもかかわらず，珪石とろ う石を分離することが可能となった。

2 ) 鉱石の浮沈は, 密度差以外にも層内の粒子や気泡 の流れ，及び粉体首の流動性に依存しており，高い 分離効率を得るためには，最適な空塔速度や鉱石投 入後の流動化時間などを検討する必要があることが 明らかとなった。

\section{Nomenclature}

D : equivalent volume diameter of silicastone and pyrophyllite

$h_{\text {sp }}$ : position of sphere from bottom

$i$ : step number

$P \quad:$ density probability

$u_{0} \quad$ : superficial velocity

$V_{\text {s.s. }}$ : bulk volume fraction of S.S.

$x_{\mathrm{i}} \quad$ : number ratio

$x_{\mathrm{f}-\mathrm{s}}$ : float-sink coefficient $x_{\mathrm{f}-\mathrm{s} \text { (silicastone) }}$ : float-sink coefficient of silicastone

(m)

(m) $\quad x_{\mathrm{f}-\mathrm{s} \text { (pyrophyllite) }}$ : float-sink coefficient of pyrophyllite

$\left(-/ 50 \mathrm{~kg} \mathrm{~m}^{-3}\right)$

$(\mathrm{m} / \mathrm{s})$

$(-)$

$(-)$

$(-)$
$\Delta x_{\mathrm{f}-\mathrm{s}}$ : difference of float-sink coefficient

$\Delta P \quad$ : pressure drop

$\rho \quad:$ density of silicastone and pyrophyllite $\left(\mathrm{kg} / \mathrm{m}^{3}\right)$

$\rho_{\mathrm{fb}} \quad$ : bulk density of fluidized bed $\quad\left(\mathrm{kg} / \mathrm{m}^{3}\right)$

$\rho_{\text {sp }} \quad$ : density of sphere 


\section{References}

1) The Society of Powder Technology, Japan, Ed. : "Terminology Dictionary of Powder Technology, 2nd Edition”, Nikkan Kougyou Shinbunsya (2000)

2) Wills, B. A. : "Mineral Processing Technology, 2nd Edition”, Pergamon Press (1981)

3 ) Association of Powder Process Industry \& Engineering, Japan, Ed. : "Fluidization Handbook", pp. 57-59, Baifuhkan (1999)

4) Bakhtiyarov, S. I. and R. A. Overfelt: "Fluidized Bed Viscosity Measurements in Reduced Gravity", Powder Technology., 99, 53-59 (1998)

5 ) Tanaka, Z., J. Oshitani, T. Nakamura, T. Syouji and
A. Horiuchi: "Development of Technology for Separating Low Grade Coals from Raw Coals by Fluidized Bed of Dry Heavy Medium", Kagaku Kogaku Ronbunshu., 26, 327-330 (2000)

6 ) Tominaga, H. : "Shigen Handbook", pp. 419-423, Maruzen (1989)

7 ) Makino, K. : “Encyclopedia of Minerals”, p. 207, Nikkan Kougyou Shinbunsya (1998)

8 ) Chiba, S., T. Chiba, A. W. Nienow and H. Kobayashi : "The Minimum Fluidization Velocity, Bed Expansion and Pressure-Drop Profile of Binary Particle Mixture", Powder Technology., 22, 255-269 (1979) 